\title{
Attachment dynamics in a virtual world.
}

Schönbrodt, F. D., \& Asendorpf, J. B. (2012). Attachment dynamics in a virtual world. Journal of Personality, 80, 429-463. doi:10.1111/j.1467-6494.2011.00736.x

The definitive version is available at www.blackwell-synergy.com:

http://onlinelibrary.wiley.com/doi/10.1111/j.1467-6494.2011.00736.x/abstract

\section{Author Note}

Felix D. Schönbrodt, Department of Psychology, Humboldt University Berlin,

Germany; Jens B. Asendorpf, Department of Psychology, Humboldt University Berlin, Germany.

Felix D. Schönbrodt is now at Department of Psychology, Ludwig-MaximiliansUniversity Munich, Germany.

Correspondence concerning this article should be addressed to Felix Schönbrodt, Leopoldstr. 13, 80802 München, Germany. Email: felix.schoenbrodt@psy.lmu.de. Phone: +49 892180 5217. Fax: +498921803000. 


\begin{abstract}
The study investigated the transfer of attachment working models onto autonomous agents in a virtual social environment (VSE). 422 participants from a community sample (mean age 29 years; mean relationship duration 4.8 years) encountered 3 attachment-related key scenes in a VSE: a separation with a subsequent reunion, a conflict, and an illness. In these scenarios, participants gave instructions to the main character (the "protagonist") who had a romantic relationship to one of the other agents (the "virtual spouse"). Recorded were numerous behaviors as well as emotions participants ascribed to the protagonist. Generally, participants' attachment styles correlated as predicted with their behavior towards the virtual spouse, with $\beta$ s up to .42. Thus, the study demonstrates that internal working models are transferred to the virtual relationship. This approach opens new ways to investigate attachment-related behavior by using VSEs that allow experimental variations of the virtual partner's reactions and other situational variables.
\end{abstract}

Keywords: transference, adult attachment, virtual environment, autonomous agents 
Attachment Dynamics in a Virtual World

Attachment theory assumes that representations of early childhood experiences and other past relationships shape an internal working model that influences perception and behavior in new relationships (Ainsworth, Blehar, Waters, \& Wall, 1978; Bowlby, 1980; Fraley, 2007). This process has also been called transference, and generally describes the phenomenon that (specific or generalized) representations of significant others influence our perception of unknown persons, as well as emotional and motivational responses towards them. The concept of transference has its roots in psychoanalysis (Gelso \& Hayes, 1998), and has recently been reconceptualized in social-cognitive terms (Andersen \& Cole, 1990; Andersen \& Thorpe, 2009; Berk \& Andersen, 2000, 2008; Saribay \& Andersen, 2007). Attachment theory has been proposed as a framework for the understanding of transference processes (Gelso \& Hayes, 1998; Mallinckrodt \& Chen, 2004), and the current study investigates how generalized working models of relationships are applied to virtual persons in an online computer game.

In most studies so far, targets of transference have been short verbal descriptions of hypothetical persons (e.g., Berk \& Andersen, 2008; Brumbaugh \& Fraley, 2006, 2007; see, however, Berk \& Andersen, 2000), which allow a high degree of controllability. However, attachment researchers themselves theorize that the attachment system primarily gets active in situations of distress or threat, and that interindividual differences in attachment style are most pronounced in such situations (Hazan, Campa, \& Gur-Yaish, 2006; Simpson \& Rholes, 1998; Simpson, Rholes, \& Phillips, 1996). Hence, vignettes might lack the social realism and situational features that are potentially necessary to trigger the attachment system (Furr, 2009; Shaver \& Mikulincer, 2006).

The current study aims at investigating how internal working models of attachment shape behavior towards an autonomous virtual spouse in an online computer game. In contrast 
to vignettes or static descriptions of persons and situations, in this game behavior in an ongoing relationship is investigated (Vicary \& Fraley, 2007) by presenting several attachment-related situations. Above that, in contrast to vignettes, interaction partners proactively act and react on participants' actions, resulting in a dynamic setting for relationship behaviors.

\section{The Transfer of Internal Working Models to Attachment-related Situations in Virtual Social Environments}

We propose a new approach to studying attachment dynamics based on identification and the transfer of internal working models: A virtual actor that is controlled by the participant serves as a target of identification processes, and an autonomous agent who serves as an attachment figure is used as a target where internal working models can be applied to. The study takes place in a virtual social environment (VSE), in which typical attachment-related situations are created. Virtual environments are advocated as promising tools in psychological research, providing a unique combination of both mundane realism and experimental control (Blascovich et al., 2002; Schönbrodt \& Asendorpf, in press b). In a VSE where interaction partners are modeled as autonomous agents, the investigation of close relationships has several distinct features in contrast to conventional methods like self-report measures, vignettes, laboratory studies, or interviews. First, the researcher has full experimental control over the actions and reactions of the virtual interaction partners. Second, special scenarios can be created that are hard or impossible to present in the laboratory with real persons (e.g. the death of a parent, or the infidelity of the romantic partner). Third, in contrast to vignettes, behavioral dynamics over time can be investigated (Schönbrodt \& Asendorpf, in press b; Vicary \& Fraley, 2007). Fourth, in contrast to vignettes, interpersonal situations in VSEs are anchored in the experiential system (McClelland, Koestner, \& Weinberger, 1989; Schultheiss, 2001). For example, situation-contingent facial expressions of the agents, background music, 
or triggered events can be used to increase the feeling of immersion of the participant and to elicit spontaneous and automatic reactions. Fifth, both data collection and data analyses can be more easily accomplished: Testing can be done over the internet, and due to automatic coding, reliable behavioral indices can be obtained without the effort of coding hours of video material.

Although some researchers already investigated social behavior in virtual environments (e.g., Frey, Blunk, \& Banse, 2006; McCall, Blascovich, Young, \& Persky, 2009), to our knowledge no such study has been conducted to investigate adult attachment.

If internal working models indeed should manifest themselves in such virtual environments, two processes have to be assumed. First, we assume that participants transfer their own emotions and behavioral tendencies to the main character in the VSE through a process of identification: Participants put themselves into the actor's position, feel with it, and let it perform behaviors as a proxy person for them. Second, internal working models of attachment are supposed to be applied to the virtual spouse.

In the implementation of our VSE, we strived to facilitate an intuitive process of identification and spontaneous behaviors, and to reduce tendencies of controlled self-portrayal or the re-enactment of mere relationship stereotypes. This approach is reflected by two design decisions. First, we argue for the use of a rather symbolic and de-individualized representation of the virtual spouses. It has be shown that representations of significant others have a high and chronic baseline of accessibility, even in the absence of any individuating cues of the target (Andersen \& Thorpe, 2009). Furthermore, while in some research settings more realistic virtual agents might enhance believability and the validity of psychological effects (e.g., Yee, Bailenson, \& Rickertsen, 2007), we argue that in our scenario it is just the indeterminism of the virtual spouse which enhances the application of internal working models (for a more detailed discussion, see Schönbrodt \& Asendorpf, in press b). This 
symbolic depiction does not necessarily constrain the interaction with virtual characters, as it has been shown that humans are capable of processing symbolic representations of persons in almost the same manner as real persons (Sanchez-Vives \& Slater, 2005). To summarize, we assume that the ideal figure would be a blank slate onto which a general working model can be projected.

Secondly, for the same reasons, we did not explicitly ask participants to identify themselves with the protagonist, nor did we introduce the virtual spouse as an avatar of the real-life partner. We assume that an explicitly prompted identification would undermine an intuitive and spontaneous flow of behavior, and rather triggers stereotyped behaviors and controlled self-portrayals. Support for this approach can be drawn from research on the assessment of implicit motives by means of picture story exercises (Schultheiss \& Pang, 2007) like the Thematic Apperception Test. Stories written to these pictures usually are written about other persons from a third person's view and are in no way explicitly tied back to the self; nonetheless valid inferences about the writer can be drawn. In some coding systems, stories written from the first person's perspective even are discarded (Waters \& Waters, 2006).

\section{The Virtual Social Environment Simoland}

According to these principles, we developed a VSE called "Simoland" which was presented as an online computer game ${ }^{1}$ (Schönbrodt \& Asendorpf, in press b). Simoland was “inhabited" by several autonomous agents called Simos (see Figure 1). In the story of the computer game, the main character whose gender was matched to that of the participant had a romantic relationship to another Simo. For clarity of description, we introduce here some labels that will be used throughout this paper: The participant-controlled Simo will be called the protagonist, its romantic partner will be called the virtual spouse or just spouse, and all

\footnotetext{
${ }^{1}$. Researchers interested in using Simoland for their own research are encouraged to contact the first author.
} 
other Simos will be called the other Simos. While all Simos were autonomous agents which interacted with each other and their environment (e.g., they searched for food, started conversations amongst each other, listened to music, etc.), participants could control the protagonist $^{2}$. Whenever the participant clicked on an object or another Simo, a list with possible actions appeared which the protagonist could perform with that object. Over 30 actions were available, and included for example: kissing, talking about hobbies, tell how you feel, flirting, dance together, etc. (for a complete list of possible actions see Schönbrodt and Asendorpf, in press b). All other Simos were autonomous agents which interacted with each other and their environment. Generally, the autonomous agents reacted according to a tit-fortat strategy (for details on the underlying model of the agents see Schönbrodt and Asendorpf, 2010, in press a).

During the game, participants encountered different scenes. Whereas the first part was identical for all participants, in the middle of the game, a key scene occurred: Each participant encountered one of three attachment-related scenes (a separation scene, a conflict with the spouse, or an illness of the protagonist) which allowed studying participants reactions on these events (for details on the scenes, see the Methods section below).

In order to increase readability of the following sections, we do not speak of the "participant's behavior", but rather of the "protagonist's behavior" - although its behavior of course is directed and initiated by the participant. Similarly, during the game we did not ask the participant for a self-report of own emotions, but rather asked "How does the protagonist feel at the moment?". Hence, we consequently speak of ascribed emotions when we refer to

${ }^{2}$. We did several pre-tests to ensure that the handling of the game is as easy and user-friendly as possible. To explore possible effects of prior experiences with computer games, a threeitem questionnaire $(\alpha=.87)$ of familiarity with computer games was assessed after the study. The highest correlation of this variable with other variables of the study was $r=.11$, and its inclusion as a covariate did not alter the reported results. 
these emotion ratings.

\section{The Present Study}

We investigated whether the attachment style of the participant, varying on the dimensions attachment Avoidance and attachment Anxiety ${ }^{3}$, can predict how participants control a protagonist's behavior towards the virtual spouse. In the current study, three different attachment-relevant situations were systematically varied between participants: a separation scene (the virtual partner has to leave for an indefinite amount of time), a conflict scene (the virtual partner wrongly accuses the protagonist of infidelity), and an illness scene (the protagonist learns to know that he or she maybe has a deadly disease). We derived three types of indices from game behavior: behavioral indices (which actions were chosen?), the physical distance between the protagonist and the virtual spouse, and emotion ascriptions. For the sequence of scenes see Figure 2.

All three scenarios pose an attachment-related threat to the protagonist. The threat, however, has a different nature in each setting. In the separation scene, the attachment figure is not available for an indefinite amount of time, and therefore the attachment bond could be challenged. In the conflict scene, the attachment figure physically is available, but the bond might be challenged due to the conflict. In the illness scene, the attachment figure is available, and the threat is from outside the relationship. Hence, in the last scenario, the bond is not challenged, and the attachment figure is theoretically available to be used as a safe haven.

\section{Hypotheses}

Based on existing literature on these attachment related key scenes, we developed specific hypotheses concerning the impact of attachment styles onto the protagonist's behavior in each scenario. If no specific hypotheses could be derived, we proposed hypotheses based on general assumptions about secondary attachment strategies (Mikulincer \& Shaver, 2005;

\footnotetext{
3. To avoid confusions, we write Avoidance and Anxiety in upper case letters when we refer to the dimensions of attachment styles.
} 
Mikulincer, Shaver, \& Pereg, 2003; Shaver \& Mikulincer, 2002): Anxious individuals are supposed to engage in hyperactivating strategies, which encompass constant vigilance and effort until an attachment figure is perceived to be available, a strong approach orientation toward relationship partners, attempts to elicit their support, as well as efforts aimed at minimizing the distance from them. Avoidant individuals, in contrast, engage in deactivating strategies, which keep the attachment system deactivated so as to avoid frustration. These strategies encompass the denial of attachment needs, avoidance of closeness and dependence in close relationships, as well as efforts to maximize the emotional and physical distance.

We furthermore explored the interaction between Anxiety and Avoidance scores. As in most previous studies this interaction turned out to be insignificant (see, however, Dewitte, Koster, De Houwer, \& Buysse, 2007), we did not expect systematic interaction effects.

Baseline situation. Participants in all conditions encountered a common part at the beginning of the game where only the protagonist and the virtual spouse were present. While one purpose of this scene was to let the participant get acquainted with the game, we also could explore the behavior towards the spouse in an unstructured situation unrelated to attachment. If identification with the protagonist occurs, the current emotions of the participants (assessed before the start of the game) should be projected onto the protagonist. As the key scene in the middle of the game is supposed to change the emotions of the protagonist, the correlations to the initial state of participants' emotions are supposed to decrease over the course of the game.

Hypothesis 1: Correlations between participants' current emotions and the ascribed emotions of the protagonist are significant at the beginning of the game.

Separation. Many researchers think that distress due to separation and loss is one of the strongest indicators of an attachment bond (Bowlby, 1980). The earliest test of attachment styles, the strange situation procedure (Ainsworth et al., 1978), is based exactly on this fact. 
What adult behavioral reactions to separations have been found so far? In a study on attachment styles and separation behaviors, Fraley and Shaver (1998) observed separating and non-separating couples in a naturalistic study at an airport. Concerning attachment styles, avoidant separating women showed less proximity seeking behaviors and more withdrawal behaviors (e.g., pulling away, or not making eye contact). Anxiety did not predict behavior, but self reported distress in women.. Diamond, Hicks, and Otter-Henderson (2008) investigated the full sequence of preseparation, separation, and reunion in a diary study of couples who experienced temporary physical separations. In their study they differentiated between the homebound partner and the traveling partner. As in our scenario the spouse leaves the protagonist (see Procedure), we focus on Diamond et al.'s results for the actor effects of the homebound partner. Amongst many other results, they found for all participants a significant decline in positive affect from the preseparation to the separation episode, as well as a significant recovery from separation to reunion. Furthermore, homebound avoidant participants initiated less remote contacts.

According to the presented findings, and based on attachment theory's general predictions, we propose that:

Hypothesis 2: Regardless of attachment style, participants ascribe (a) a decline of positive emotions to the protagonist during separation, and (b) an increase of positive emotions during reunion.

Concerning attachment Avoidance, we propose the following hypotheses:

Hypothesis 3: During the Separation scene, individuals high in Avoidance control the protagonist such that it (a) keeps less contact to the absent spouse, and (b) does not show distress.

Hypothesis 4: During the Reunion scene, individuals high in Avoidance control the protagonist such that it actively avoids contact with the spouse. That means it (a) keeps a 
greater physical distance, (b) initiates less interactions in general and in particular (c) less positive interactions, and (d) does not feel emotionally relieved by the reunion.

Concerning attachment Anxiety, we propose the following hypotheses:

Hypothesis 5: During the Separation scene, individuals high in Anxiety control the protagonist such that it keeps the contact to the absent spouse by (a) thinking of the spouse and (b) writing letters to him or her; also, anxious participants (c) ascribe a stronger decline of positive emotions to the protagonist.

Hypothesis 6: During the Reunion scene, individuals high in Anxiety control the protagonist such that it tries to reassure the bond by an increased frequency of interactions.

Conflict. In the Conflict condition, the spouse wrongly accuses the protagonist of infidelity. In their literature review of the connection between attachment styles and emotions in close relationships, Mikulincer and Shaver (2005) summarized reactions from anxious and avoidant people to negative behaviors of their partners. Amongst others, they reported the following results for individuals scoring high on attachment Avoidance: (a) they show a mixture of suppressed anger (i.e., they do not consciously report anger) and high levels of hostility (Mikulincer, 1998); (b) they use distancing strategies to the partner (Mikulincer, 1998); (c) after a negative relational episode, they are less likely to forgive a partner who had hurt them, which is manifested in a strong desire for revenge as well as negative feelings (Mikulincer \& Shaver, 2005). Translated to Simoland, we propose the following hypotheses:

Hypothesis 7: Avoidant individuals control the protagonist such that it (a) does not show decreasing positive emotions during conflict, but instead expresses its hostility by exhibiting (b) more negative and (c) less positive behaviors.

Hypothesis 8: Avoidant individuals control the protagonist such that it uses distancing strategies during conflict by (a) keeping a greater physical distance and (b) initiating fewer interactions with the spouse. 
Hypothesis 9: After the conflict, avoidant individuals control the protagonist such that it shows (a) more negative behaviors towards the spouse (desire for revenge), (b) less positive behaviors towards the spouse, and (c) no recovery of positive emotions.

Concerning individuals high in attachment Anxiety, predictions are less clear as these individuals are supposed to "react to a partner's negative behaviors with a complex mixture of resentment, hostility, anger, self-criticism, fear, sadness, and depression” (Mikulincer \& Shaver, 2005, p. 155). In a diary study about the perception of conflict, Campbell, Simpson, Boldry, and Kashy (2005) found that anxious individuals showed more self-reported distress during conflict (see also Simpson et al., 1996).

Hypothesis 10: Anxious individuals ascribe more feelings of distress to the protagonist during conflict.

Illness. In the Illness condition, a doctor tells the protagonist that he or she presumably has a deadly disease (later in the game, it is revealed that it only was a false alarm). This scenario was designed to assess, whether the virtual spouse is used as a safe haven. For avoidant persons, under conditions of stress the attachment should be suppressed (deactivating strategy), and consequently less support seeking behavior should be shown (Mikulincer \& Florian, 1998; Mikulincer \& Shaver, 2005; Rholes, Simpson, \& Oriña, 1999):

Hypothesis 11: In the Illness scene, individuals high in Avoidance control the protagonist such that it (a) initiates fewer interactions overall and (b) shows less support seeking behavior.

As the spouse is at some physical distance during the Illness scene (see Procedure), we do not expect an increased distance for avoidant individuals. During the Comfort scene, however, the spouse actively decreases the distance. Only in this situation, the deactivating system should be in charge:

Hypothesis 12: Participants' Avoidance is (a) unrelated to the physical distance between 
the protagonist and its virtual spouse in the Illness scene, and (b) positively related to physical distance in the Comfort scene.

In a key study on the interplay between adult attachment and threatening conditions, Simpson, Rholes, and Nelligan (1992) investigated behavioral reactions of women who waited together with their partners for an anxiety-provoking situation. Against expectations, they found no relation between interindividual differences in attachment Anxiety and support seeking behavior. Hence, theoretical predictions and previous empirical results do not fully correspond. Anyway, we propose the following hypothesis derived from theory:

Hypothesis 13: During the Illness scene, individuals high in Anxiety control the protagonist such that it stays closer to the spouse and initiates more interactions overall.

Concerning Avoidance, Simpson et al. found an interaction between observer-rated stress and Avoidance on the amount of observer-rated comfort seeking: For securely attached persons, comfort seeking increased with increasing stress, while for avoidant persons comfort seeking decreased with increasing stress. In another study, however, this result could not be replicated for men (Simpson, Rholes, Oriña, \& Grich, 2002). As previous results on support seeking are mixed, we did not formulate a directed hypothesis, but explored, whether we could replicate the interaction found by Simpson et al. (1992).

\section{Method}

\section{Participants}

A community sample was recruited to participate in an online experiment advertised on the online portal of the Department of Psychology, Humboldt-University Berlin (www.psytests.de). The announcement of the study required participants to be at least 18 years old and to be currently involved in a serious, heterosexual relationship with a relationship duration of at least six months. After removal of participants who did not meet these requirements, 422 participants remained in the final data set (Separation: 144, Conflict: 
131, Illness: 147). The average age was 28.53 years $(S D=9.67$; range 18 to 65 years), 353 participants were female. Average relationship duration was 4.82 years $(S D=6.68$; range $=6$ months to 42 years). As an incentive for participation, participants received a personality profile based on their individual responses directly after the experiment.

\section{Procedure}

The first part of the game was identical for each participant. After that common part, randomly one of the three key scenes was presented (see Figure 2). In the next sections all scenes are described; for the ease of description, the scenes are consistently described from a male participant's point of view (i.e., the protagonist is male and the virtual spouse is female).

The common part: Introduction / Dyad / All-Together. The first 7 minutes of game play were identical for each participant. At the beginning of the game, the protagonist was alone in Simoland, giving the participant the opportunity to learn the handling of the game and to learn the interaction with inanimate objects ("Introduction"; in the following text, scene names are always referred to in uppercase names). Behavior in Simoland should be spontaneous, hence we did not give any instructions about how the participant should behave (e.g., we did not tell participants that they should treat the virtual spouse the same way as they would treat their real-life partner). Additionally, we instructed participants to play freely and that no goals are to be achieved. In order to increase the social significance of their actions (Furr, 2009), however, it was pointed out that every choice they made had an effect on the mood and the behavior of the other Simos and would affect their relationship.

Next, the virtual spouse was introduced. For the next three minutes, the couple was alone in Simoland ("Dyad"). Participants could freely choose to instruct their protagonists to interact or not with the spouse. As the last scene of the common part, several other Simos were introduced into the game ("All together"). These other Simos were introduced to provide an opportunity to interact with other Simos than the spouse, and to prevent spouse-directed 
interactions due to pure boredom. At the end of this scene, one of the following three key scenes was presented, depending on the experimental condition.

Separation. The rationale behind this scene was to induce a separation which was due to external factors (i.e., not a separation due to an unsatisfied relationship). At the beginning of this scenario a pre-scripted cut scene was shown (during cut scenes, participants could not give commands to the protagonist). The spouse approached the protagonist and told him that a near relative of her has died. She further told him that she had to go to a far-away town, which was a very dangerous journey, and that it was uncertain when she will return. Then, the spouse started to cry because of the separation. She walked away, but then returned, gave her partner a kiss, and then finally went away, still crying. The whole scene was accompanied by a very sad song ("Ne me quitte pas" from Jaques Brel), and at the end the screen was slowly faded out to black. After a couple of seconds, the cut scene was ended with a fade-in of the screen (a new day began) and participants could again give commands to the protagonist. For the following 3 minutes ("Separation") the protagonist stayed alone, uncertain about the return of the spouse. After that period, night fell again. At the dawn of the next morning, a message was displayed that the spouse returned safely, and the spouse approached the protagonist from the edge of the game world ("Reunion"). Hence, the scene was an analogue of the strange situation procedure known from infant attachment research (Ainsworth et al., 1978).

Conflict. The rationale of this scene was to induce a conflict into the virtual relationship. As several pretests showed that it is rather difficult to evoke negative behaviors in Simoland, a rather strong manipulation was chosen: The spouse came to the protagonist and yelled at him that she heard gossip about him cheating her with another woman. The spouse displayed very strong anger (see Figure 1), started to argue, and left. For the next three minutes ("Conflict"), the spouse had a special behavioral scheme: She never initiated an 
interaction with the protagonist, and for the next three interactions initiated by the participant, she reacted angry and rejected the protagonist (regardless the positivity of the protagonists' approach). After that, it fell night in Simoland. At the next dawn, the spouse was internally reset to her normal tit-for-tat mode of behavior ("Next day

Illness. The rationale of this scene was to induce a threat for the protagonist to see whether the spouse is used as a safe haven. In this scene ("Illness") a doctor was introduced with the words that the protagonist now has a routine checkup. The doctor delivered some bad news: the protagonist probably had a deadly disease. The diagnosis is not definite yet, but if he had the disease, he would have to die within 3 weeks. The doctor emphasized that the disease was not contagious at all (i.e., the protagonist could approach the virtual spouse without risking to infect her). The spouse, who did not know anything about the disease yet, stayed at the edge of the screen. At first, the spouse did not approach the protagonist actively, but she reacted positively if the participant initiated an interaction. After three minutes, the spouse actively approached the protagonist and offered comfort by saying "Should I comfort you?" ("Comfort"). One minute before the end of the game, the doctor delivered good news: It was a false diagnosis, the protagonist is not sick at all ("Happy End").

Outro. At the end of the game, in each condition a message appeared that in one minute the game would be over. Starting with this message, a slow fade out started, until the screen was black. After that, several questionnaires (see below) were assessed.

Emotion ascriptions during the game. At five predefined points the game was paused without prior announcement and a short questionnaire was displayed. We asked the participant which emotions the protagonist currently experiences (see Figure 2 for the timings of these ratings). The scales were chosen to reflect emotional reactions important to attachment related issues (sad - lonely; lonesome - safe/protected; angry - peaceful; anxious confident; strained - relieved; disappointed - trustful; weak - strong). These emotion ratings 
were assessed with 7 bipolar Likert scales. The positive side of each scale was counterbalanced between left and right.

Current Emotions. Prior to the start of the game, we asked for participants' current emotions using the PANAVA-KS questionnaire (Schallberger, 2005). This questionnaire assesses current emotions on three scales (Cronbach's $\alpha$ s $>.72$ ): positive affect (4 items), negative affect (4 items), and valence ( 2 items). For better comparability with our bipolar scales from the game, all analyses were performed with the difference score between positive affect and negative affect.

Attachment Scales. To assess attachment styles, we employed a short version of the revised Experiences in Close Relationships questionnaire (ECR-R; Fraley, Waller, \& Brennan, 2000). This questionnaire assesses generalized attachment Anxiety and Avoidance each with ten items on a 7-point Likert scale. Both scales showed a good internal consistency ( $\alpha \mathrm{s}>.88)$.

Identification with the protagonist. After the game, two items were assessed on a 5point Likert scale ranging from 1 (not at all) to 5 (very much): "I identified myself with the protagonist" and "It often occurred to me that the Simos only were computer agents" (reverse keyed). Both items were averaged to a scale of identification $(\alpha=.62)$.

Demographic data. We assessed the relationship duration with the current partner, the age, and the gender of the participants.

\section{Statistical Procedure}

As data analytic strategy, we analyzed the common part of the game for the combined sample. After that, each scenario is reported in a separate section. During the game, three types of indices were measured: the interactional options participants selected, the physical distance between the protagonist and the spouse, and the emotion ascriptions.

Interactional choices. Comparable to previous research in couple interactions (e.g. Gottman \& Levenson, 1992), all possible behaviors were a priori categorized into positive, 
neutral, and negative actions (for details of possible actions and categorizations, see Schönbrodt \& Asendorpf, in press b). We then calculated three game indices from aggregated behavioral choices towards the spouse: the ratio of positive actions to all actions (positivity), the ratio of negative actions to all actions (negativity), and the interaction frequency to the spouse divided by all interactions with inhabitants of Simoland (spouse-directedness). Thus, all indices were standardized relative to the overall number of actions of each participant.

The positivity index included 11 actions (e.g., kissing, talking about one's mood, talk about the relationship, ask how the other feels), and the negativity index included 7 actions (e.g., send the other away, criticize, insult, start an argument); further actions were categorized as neutral (e.g., talk about hobbies, talk about occupational successes, gossip about other people). For the Illness condition, we calculated an additional behavioral index called "support seeking", which included following actions: tell your spouse how you feel at the moment, talk about the recent events, call the spouse, think of the spouse.

Physical distance. We furthermore calculated the mean physical distance between the protagonist and the virtual spouse for each scene. As the distribution of all distances was skewed to the right, all distances were transformed by a $1 / x$ transformation. Single outliers with a $z$ value $>3$ were winsorized (i.e., their value was set to a raw value corresponding to the $z$ value of 3; Wilcox, 2005), which further improved the normality of the distribution.

Emotion ascriptions. As the seven Likert scales of the in-game emotion ratings were highly homogenous (Cronbach's $\alpha$ in each assessment $>.80$ ), they were combined to an average score. All further analyses were done with this average emotion rating. To test our hypotheses about intra-individual changes in the level of positive emotions, we added the emotion rating from the prior scene as control variable into multiple regression models, referred to as "emotion baseline" (e.g., to test for the emotional drop down due to the separation, we predicted the emotional rating from the Separation scene while controlling for 
the base line rating from the prior scene All Together). The difference from the scene All together to the key scene will be labeled "emotional drop down", and the change from the key scene to the following scene will be labeled "emotional recovery".

Using hierarchical multiple regressions, we regressed these game indices onto attachment Anxiety and Avoidance. To control for gender and the log-transformed relationship duration, these variables were entered in Block 1 (in the case of emotional drop down and recovery we also added the emotion ascription from the previous scene as additional control variable). Attachment Anxiety and Avoidance were entered as main effects in Block 2, and the size and significance of the incremental validity $\left(\Delta R^{2}\right)$ was evaluated. As ancillary analyses, we also entered the Anxiety X Avoidance interaction as Block 3.

\section{Results}

Descriptive statistics of all game indices, the attachment scales, and the current emotions are displayed in Table 1.

\section{Identification with the Protagonist}

Seventy-two percent of participants reported an identification with the protagonist (i.e., they had a value above the scale labeled $3=$ undecided), 16\% had below-midpoint scores. Overall, participants had a mean value of $3.63(S D=0.91)$. Thus, a large majority of the participants seems to have identified with the protagonist. Attachment dimensions did not correlate with the amount of identification $(r<.04, n s$.$) .$

\section{The Course of Emotions}

The descriptive course of emotion ascriptions in all conditions is displayed in Figure 3. In all conditions, a major decline of positive emotions occurred in the key scene. Linear mixed effect models were used to test whether this decline was significant, and whether differences between conditions occur. For that, we calculated a planned contrast between the key scene and the four other scenes, as well as post hoc pairwise comparisons of the three 
conditions to assess potential differences between them. Participants were entered as random factor to control for differences in the initial state of emotion ascriptions.

The analysis revealed that the contrast between the key scene and the other scenes was highly significant $(F(1,1681)=1928.66, p<.001)$. Hence, the experimental manipulation effectively influenced participants' perception of the situations. The main effect of the experimental condition on emotion ratings also was significant $(F(2,418)=13.74, p<.001)$, as was the interaction between the contrast and the experimental condition $(F(2,1681)=17.57$, $p<.001)$. As can be inferred from Figure 3, pairwise comparisons between the three conditions showed that in the Separation scene emotional ascriptions were significantly more positive $(p<.001)$ than in the other two conditions, which did not differ among each other $(p$ $=.91)$. An additional analysis revealed, however, that the decline of positive emotions within the Separation condition was significant as well $(F(1,571)=458.39, p<.001)$, which supports Hypothesis 2.

\section{Transfer of Current Emotions to the Protagonist}

We asked for the current emotions of participants immediately before the game took place. If a transfer of emotions to the protagonist appeared, these emotional ratings should correlate with the emotions ascribed to the protagonist at the beginning of the game. Pearson correlations between the PANAVA difference score and the emotion ascriptions in the game scenes were $r=.30, .21, .12, .17$, and $.17(n=422$, all $p \mathrm{~s}<.05$; see Figure 2 for timings of emotion ratings). Hence, we found a congruency between the initial emotions of participants right before the game and the protagonists' emotion at the beginning of the game. Situational features of the game are supposed to change the emotions ascribed to the protagonist, and indeed the interrelation to participants' initial emotions declines in later scenes of the game.

In addition, we explored the impact of attachment dimensions on the amount of this identification (Mikulincer \& Horesh, 1999). For none of the emotion ratings attachment 
dimensions had a significant moderating impact as tested by moderated regressions.

\section{The Common Part}

Table 2 reports the results of the multiple regressions. In the Dyad scene, avoidant participants commanded the protagonist to show less positive and more negative behaviors towards the spouse. When the other Simos were introduced, attachment styles did not predict any spouse directed behavior.

\section{Separation}

Results from the multiple regression analyses are reported in Table 3. No face-to-face interaction with the spouse was possible during the Separation scene. Nonetheless, participants could instruct the protagonist to show two spouse related behaviors: a) Writing a letter to him or her. Out of 146 participants, 29 wrote a letter once, and two participants twice;

b) Thinking of the spouse. Out of 146 participants, 63 thought once of the spouse, 12 twice, 6 three times, and 1 participant four times. As both variables were heavily skewed, for analyses we dichotomized the variable for protagonists who did $(=1)$ and did not write a letter $(=0)$, respectively did or did not think of the spouse.

During separation, the Avoidance score did not predict contact maintenance behavior; neither did avoidant participants ascribe a smaller emotional drop down to the protagonist. Hence, Hypothesis 3 could not be confirmed. During reunion, however, the protagonists of avoidant participants had a higher physical distance, initiated less interactions overall and less positive interactions in particular to the spouse. Furthermore, avoidant participants did not ascribe an emotional recovery to the protagonist. These findings fully support Hypothesis 4 and demonstrate a replication of Ainsworth et al.'s classic description of avoidant behavior during the reunion phase.

Thinking of the spouse, but not writing a letter, correlated with Anxiety, which partially supports Hypothesis 5. Further support for this hypothesis could be found concerning emotion 
ascriptions: The higher the Anxiety score of the participant, the higher was the ascribed emotional drop down during separation. In contrast to Hypothesis 6, Anxiety did not significantly predict any dependent variable in the Reunion scene. Only one coefficient showed a tendency into the expected direction: anxious individuals tended to initiate more interactions to the spouse $(\beta=.15, p=.089)$. This finding, however, is in line with the women's results in the study on airport separations (Fraley \& Shaver, 1998). In this study, Anxiety as well predicted self-reported distress, but not overt behavior.

\section{Conflict}

For results, see Table 4. During conflict, the protagonists of individuals high in Avoidance showed signs of heightened hostility by expressing less positive (although not more negative) behaviors towards the spouse. In contrast to Hypothesis 7, however, Avoidance did not correlate negatively with the emotional drop down. Hence, Hypothesis 7 was only partially supported. Most prominent, however, are the significant distancing strategies: the protagonists of avoidant individuals had a greater physical distance and initiated fewer interactions to the spouse (Hypothesis 8). Finally, the expected desire for revenge after the negative episode was very pronounced in the Next Day scene: avoidant individuals instructed their protagonists to show less positive and more negative behaviors towards the spouse. Furthermore, they ascribed less positive feelings to the protagonist and the ascribed recovery of positive emotions was less pronounced, which fully supports Hypothesis 9.

Concerning attachment Anxiety we found support for Hypothesis 10: Anxious individuals ascribed more negative emotions to the protagonist. Hence, cues of possible rejection are perceived as more pronounced by anxious individuals.

\section{Illness}

For results, see Table 5. During the Illness scene, no significant coefficients concerning 
the behavioral indices could be found for attachment Avoidance. One coefficient, however, showed a tendency into the expected direction: the protagonists of avoidant individuals showed less spouse-directedness $(\beta=-.15, p=.084)$. Hence, Hypothesis 11 could only partially be supported. As expected (Hypothesis 12), avoidant participants neither increased nor decreased the physical distance of their protagonists during the Illness scene. In the Comfort scene, however, they showed a reaction: After the virtual spouse actively approached the protagonist and offered comfort, avoidant participants instructed their protagonists to significantly increase the physical distance to the spouse (note, however, that although the beta weight was significant, $\Delta R^{2}$ did not fully reach significance).

Concerning Anxiety, we found that anxious individuals' protagonists stayed closer to the spouse during the Illness scene, as expected (Hypothesis 13). On the other hand, these individuals did not instruct their protagonists to initiate more interactions, nor did they increase their ratio of positive interactions to the spouse. Hence, while the decreased distance is in line with theoretical predictions, the behavioral null results concerning Anxiety found by Simpson et al. (1992) could be replicated as well.

Using hierarchical regression analyses, we analyzed the interaction between Avoidance and the ascribed emotions during the Illness scene in the prediction of support seeking behavior. Neither the main effects, nor the interaction term reached significance ( $p s>.222)$.

\section{Additional analyses: Interactions and Moderations}

We explored the interaction of Anxiety and Avoidance in all analyses described above. Due to the large number of statistical tests, we adjusted the level of significance with a stepwise Bonferroni correction (Holm, 1979). After this correction, no interaction term remained significant. Furthermore, we explored whether the amount of identification moderated the reported effects of attachment dimensions on game indexes. Therefore, we added the identification scale value as additional main effect as well as its interactions with 
the attachment dimensions to the multiple regression models. After adjusting the level of significance, neither the main effects nor interactions with identification reached significance.

\section{Discussion}

To our knowledge, this is the first study that observes attachment processes from human adults in virtual environments and demonstrates that internal working models of attachment are applied to an agent in a virtual social environment. We created three different attachmentrelated scenes in our VSE and could show that the attachment style of participants influenced the way they treated the virtual spouse. We derived specific hypotheses from existing literature and found full support for 7 of our 13 hypotheses, and partial support for 4 hypotheses.

In the Separation condition we recreated parts of the classic strange situation procedure: Unexpectedly, the virtual spouse had to leave with an uncertain return. Anxious individuals instructed their protagonist to think more often of the spouse during separation, and ascribed stronger negative emotional reactions to them. As expected, Avoidance was predictive during the reunion episode: When the spouse returned in a lucky turn, protagonists under avoidant individuals' control acted less spouse directed, kept a higher physical distance, and showed less positive interactions with the spouse. Furthermore, these participants ascribed less emotional relieve to the protagonist, supporting the assumption that avoidant individuals were largely unaffected by the reunion. Their behavior showed a striking similarity with the behavior of insecure avoidant children in the strange situation procedure (Ainsworth et al., 1978). In previous studies that have investigated behavior in naturally occurring couple separations (Fraley \& Shaver, 1998; Diamond et al., 2008), the separation always was anticipated by the participants, or it was not possible to observe the behavior during the separation or the reunion episode. This inevitable restriction of field studies is unfortunate, as in the original work of the strange situation it was argued that it is just the reunion episode 
which has a high diagnostic value (Ainsworth et al., 1978). To our knowledge, the current study is the first that investigates behavioral reactions of adults (albeit, not their own but instructions to an avatar) both to an unannounced separation and to the reunion. This highlights the flexibility of the VSE approach to create situations that are difficult to create in vivo.

The Conflict condition was created to induce a threat that endangers the attachment bond. Again, anxious individuals ascribed a stronger negative emotional reaction during conflict. As in the separation scene, behavior only was predicted by Avoidance. Avoidant participants expressed their deactivating strategy during conflict by instructing the protagonist to keep a greater distance, with less spouse-directed interactions overall and less positive interactions in particular. When the spouse was in good mood again, only avoidant participants' protagonists still showed less positive behaviors. Furthermore, they had a grudge against their spouses, and showed more negative behaviors and more negative emotions. The expected desire for revenge (Mikulincer \& Shaver, 2005) clearly could be shown.

The Illness condition was created to test whether participants use the virtual spouse as a safe haven in times of an external threat. In this condition, attachment styles only had a minor impact on how participants control their Simo. As expected, anxious participants instructed their protagonists to stay closer to the spouse. When the spouse in turn actively reduced the distance, avoidant participants were in pressure to re-regulate the distance by significantly increasing it. This finding again demonstrates the possibilities of experimentally manipulating the interaction partner's behavior. Apart from physical distance, no other behavioral indices showed correlations to attachment styles. One possible reason is that our specific implementation of a rapid, life-threatening disease was too far away from the everyday experiences of our participants. We also could not replicate the interaction between attachment style and intensity of experienced threat found by Simpson et al. (1992). This 
might be due to the same reasons.

The majority of participants identified with the protagonist, even though we did not explicitly instruct them to do so. The amount of identification did not moderate the results, which suggests that behaviors assessed in VSEs are valid for all participants, regardless whether they get immersed into the virtual environment or not (for similar results see Schönbrodt \& Asendorpf, in press b). Furthermore, as attachment styles were unrelated to the amount of identification, the more detached behaviors of individuals high in Avoidance cannot be attributed to a lower amount of identification.

In cases where behavioral indices did not reach significance, they were often behavioral indices composed of single indicators. However, it has been repeatedly demonstrated that correlations between traits and actual behavior only reach significance if behavioral indicators are aggregated over different behaviors and over a sufficient period of time (Epstein, 1979). Considering that in our study behavioral aggregation only took place over two or three minutes, correlations with both attachment dimensions were rather high.

\section{Strengths of the Current Study}

The current study contributes to the existing literature in two major ways. First, we introduce a new method to investigate internal working models and attachment behaviors in close relationships, and showed its validity by replicating several results from existing realworld studies in a virtual setting. The use of VSEs promises to be a key technique in future investigations of social phenomena, as it opens up an unknown flexibility in the experimental manipulation of situations and of the behavior of interaction partners. Within this 15-minute study, dynamic behavior in a broad range of attachment-related situations could be investigated, which would have been difficult in the field or in the laboratory. Moreover, scenes were created that hardly could have been made up with real persons.

In the current study we sought to replicate some classic findings. Now that the VSE 
framework is established, it is relatively easy to construct new scenarios and to explore new realms of attachment-related behavior. Furthermore, technical hurdles are not as high as some readers may assume. Simple two-dimensional characters that are geometric shapes rather than fancy avatars are sufficient to qualify them as targets of internal working models. Moreover, we argue that in the study of close relationships these symbolic depictions even work better because visual inconsistencies with the real-life partner prevent a successful immersion into the game (Schönbrodt \& Asendorpf, in press b). This facilitates the creation and the distribution of VSEs, as both technical and financial requirements are clearly reduced in comparison to more elaborate virtual environments. In contrast to visual realism, we argue that the psychological model of the agents should have a much higher priority. Unfortunately, the interdisciplinary exchange between psychologists and the virtual agents community that implements psychological models still is rather scarce. Most psychological theories lack the computational and conceptual details that would be necessary to implement them in an autonomous agent, and in some areas like non-verbal behavior or communication a lot of psychological knowledge about specific processes simply is lacking. Many current implementations of autonomous agents therefore rely on ad hoc models which are barely based on empirical findings (Krämer, Bente, Eschenburg, \& Troitzsch, 2009; Schönbrodt \& Asendorpf, 2010). Clearly, future research is needed to further clarify how psychological models can be incorporated into agents and how humans react on them.

Second, this study also contributes to current attachment literature, beyond the replication of existing findings. Fraley and Shaver (2000) have proposed that Anxiety refers to the motivation to monitor and appraise events that are related to attachment-related issues. Avoidance, in contrast, is supposed to regulate behavioral responses to attachment-related issues. Along with that reasoning, our results show that Anxiety nearly exclusively is related to emotional appraisals and not to behavior, a finding that is consistent with several other 
studies (e.g., Fraley \& Shaver, 1998; Simpson et al. 1992). Behavioral reactions, in contrast, nearly exclusively were predicted by Avoidance in the current study. Hence, our study generally supports Fraley and Shaver's (2000) emotional vs. behavioral regulation model. In addition, our results indicate a further distinction between these two attachment dimensions on a temporal dimension. Two of the three investigated scenes pose a threat to the attachment bond (Separation and Conflict; the Illness scene in contrast introduces a danger for the protagonist but not a threat to the attachment bond per se). While the appraisal of these attachment threats in the Separation and the Conflict scene - the emotional negativation only is guided by Anxiety, a sort of "secondary appraisal" takes place after the relational threat is over. This emotional recovery only is guided by the Avoidance dimension and not by the Anxiety dimension. This temporal sequence of the attachment process suggests that at the beginning Anxiety imposes a hypervigilance in the detection of potential attachment-related threats, while the subsequent avoidant reaction is the inhibition of emotional expressions (Fraley \& Shaver, 2000). Probably for the first time, this temporal sequence in emotional appraisals could be empirically confirmed.

\section{Limitations}

The community sample of the current study had $84 \%$ female participants. Hence, it is questionable whether our results generalize to both genders in the same way. We controlled for gender in our analyses, but separate analyses of genders were not recommendable due to the low statistical power resulting from the small sample size of men. Furthermore, we acknowledge that our internet sample was less controllable than a sample under laboratory conditions, and that the results based on the self-report measure of attachment style may be biased by social desirability tendencies. Although our reasoning suggests that it is the stable internal working model that influences behavior in Simoland, the correlational nature of our findings does not allow final conclusions about the causal direction. Concerning our 
hypothesis on the transfer of current emotions to the protagonist, an alternative explanation for the reported correlations could be that participants use their current emotional state as an anchor for emotional ascriptions to any other target (i.e., they are not necessarily a sign of a specific identification with the protagonist). Hence, this finding should be regarded as preliminary evidence which awaits further confirmation.

\section{Future Studies}

The proposed VSE framework can be applied to numerous other fields in psychology. For example, social computer games could be used both to instigate specific motives and to provide opportunities to realize them, or to create various kinds of emotion-arousing situations in order to study emotional processes as they unfold over time. Concerning attachment research, specific properties of the internal working models can be investigated. While attachment researchers conceptualized internal working models mostly as generalized knowledge structures, many have emphasized the representations of specific dyadic relationships (e.g., Baldwin, Keelan, Fehr, Enns, \& Koh-Rangarajoo, 1996; Cook, 2000). Particularly in the social-cognitive tradition of transference, researchers argue that any kind of felt security is grounded in specific relationships and thus is linked to distinct significant-other representations (Saribay \& Andersen, 2007). In the current study, we measured a generalized working model with a self-report questionnaire. Future studies could explore whether relationship-specific measures of attachment qualities or the experimental manipulation of the similarity of the virtual spouse to a past relationship allow new conclusions about the structure of working models.

A lot of current research investigates implicit constructs. In such diverse research fields as implicit personality self-concept (e.g. Asendorpf, Banse, \& Mücke, 2002; Egloff \& Schmukle, 2002), implicit attitudes (for an overview, see Greenwald, Poehlman, Uhlmann, \& Banaji, 2009), implicit motives (McClelland et al., 1989; Spangler, 1992), or implicit working 
models of attachment (Roisman et al., 2007, Study 3) it has been shown that indirect measures of these implicit constructs often correlate more strongly with spontaneous and uncontrolled behavioral outcomes while direct self-report measures of corresponding explicit constructs more strongly correlate with other self-report measures and with controlled behavioral outcomes. Hence, it would be fruitful to compare the predictive validity of direct measures of attachment styles (e.g., the ECR, or the Relationship Questionnaire, Bartholomew \& Horowitz, 1991) and indirect measures of attachment styles (Adult Attachment Interview, Main \& Goldwyn, 1998; or the assessment of secure base scripts with the word-prompttechnique, Waters \& Waters, 2006) with regard to behavioral outcomes in Simoland.

A possible general objection against the use of virtual environments for the observation of behavior would be the assumption that virtual behavior is completely arbitrary and unrelated to real life. Our results clearly indicate that this is not necessarily the case: Under appropriate conditions, virtual behavior reflects real life behavior. More studies, however, are needed to shed light onto the specific relation between virtual and real behavior: Do participants express virtual behaviors that they would like to express in reality, but are afraid to do for some reasons? Or do participants express the same behaviors they would have shown in a comparable situation in reality? Put in other words: Do participants live out their actual self, an ideal self, or maybe even a suppressed self? Possibly, it is a mixture of these and the design of the VSE might influence the exact mix. In any way, future studies will be necessary to shed light on this and other questions to deepen our understanding of human behavior in virtual environments and in general. 


\section{References}

Ainsworth, M., Blehar, M. C., Waters, E., \& Wall, S. (1978). Patterns of attachment: A psychological study of the strange situation. Hillsdale: Lawrence Erlbaum Associates.

Andersen, S. M., \& Cole, S. (1990). "Do I know you?": The role of significant others in general social perception. Journal of Personality and Social Psychology, 59, 384-399.

Andersen, S. M., \& Thorpe, J. S. (2009). An IF-THEN theory of personality: Significant others and the relational self. Journal of Research in Personality, 43, 163-170.

Andersen, S. M., Reznik, I., \& Glassman, N. S. (2005). The unconscious relational self. In R. Hassin, J. S. Uleman, \& J. A. Bargh (Eds.), The new unconscious (pp. 421-481). New York: Oxford University Press.

Asendorpf, J. B., Banse, R., \& Mücke, D. (2002). Double dissociation between implicit and explicit personality self-concept: The case of shy behavior. Journal of Personality and Social Psychology, 83, 380-393.

Baldwin, M. W., Keelan, J. P. R., Fehr, B., Enns, V., \& Koh-Rangarajoo, E. (1996). Socialcognitive conceptualization of attachment working models: Availability and accessibility effects. Journal of Personality and Social Psychology, 71, 94-109.

Bartholomew, K., \& Horowitz, L. M. (1991). Attachment styles among young adults: A test of a four-category model. Journal of Personality and Social Psychology, 61, 226-244.

Berk, M., \& Andersen, S. M. (2000). The impact of past relationships on interpersonal behavior: Behavioral confirmation in the social-cognitive process of transference. Journal of Personality and Social Psychology, 79, 546-562.

Berk, M., \& Andersen, S. M. (2008). The sting of lack of affection: Chronic goal dissatisfaction in transference. Self and Identity, 7, 393-412.

Blascovich, J., Loomis, J., Beall, A. C., Swinth, K. R., Hoyt, C. L., \& Bailenson, J. N. (2002). Immersive virtual environment technology as a methodological tool for social 
psychology. Psychological Inquiry, 13, 103-124.

Bowlby, J. (1980). Attachment and loss. New York: Basic Books.

Brumbaugh, C. C., \& Fraley, R. C. (2006). Transference and attachment: How do attachment patterns get carried forward from one relationship to the next? Personality and Social Psychology Bulletin, 32, 552-560.

Brumbaugh, C. C., \& Fraley, R. C. (2007). Transference of attachment patterns: How important relationships influence feelings toward novel people. Personal Relationships, $14,513-530$

Campbell, L., Simpson, J. A., Boldry, J., \& Kashy, D. A. (2005). Perceptions of conflict and support in romantic relationships: The role of attachment anxiety. Journal of Personality and Social Psychology, 88, 510-531.

Cook, W. L. (2000). Understanding attachment security in family context. Journal of Personality and Social Psychology, 78, 285-294.

Dewitte, M., Koster, E. H. W., De Houwer, J., \& Buysse, A. (2007). Attentive processing of threat and adult attachment: A dot-probe study. Behaviour Research and Therapy, 45, 1307-1317.

Diamond, L. M., Hicks, A. M., \& Otter-Henderson, K. D. (2008). Every time you go away: Changes in affect, behavior, and physiology associated with travel-related separations from romantic partners. Journal of Personality and Social Psychology, 95, 385-403.

Egloff, B., \& Schmukle, S. C. (2002). Predictive validity of an implicit association test for assessing anxiety. Journal of Personality and Social Psychology, 83, 1441-1455.

Epstein, S. (1979). The stability of behavior: I. On predicting most of the people much of the time. Journal of Personality and Social Psychology, 37, 1097-1126.

Fraley, R. C. (2007). A connectionist approach to the organization and continuity of working models of attachment. Journal of Personality, 75, 1157-1180. 
Fraley, R. C., \& Shaver, P. R. (1998). Airport separations: A naturalistic study of adult attachment dynamics in separating couples. Journal of Personality and Social Psychology, 75, 1198-1212.

Fraley, R. C., \& Shaver, P. R. (2000). Adult romantic attachment: Theoretical developments, emerging controversies, and unanswered questions. Review of General Psychology, 4, 132-154.

Fraley, R. C., Waller, N. G., \& Brennan, K. A. (2000). An item response theory analysis of self-report measures of adult attachment. Journal of Personality and Social Psychology, $78,350-365$.

Frey, A., Blunk, H. A., \& Banse, R. (2006). Psi-Land: Paarinteraktionsforschung in einer virtuellen Umgebung [Psi-Land: Investigating interactive behaviour in romantic couples in a virtual environment.]. Zeitschrift für Sozialpsychologie, 37, 151-159.

Furr, R. M. (2009). Personality psychology as a truely behavioral science. European Journal of Personality, 23, 369-401.

Gelso, C. J., \& Hayes, J. A. (1998). The psychotherapy relationship: Theory, research, and practice. New York, NY, US: Wiley.

Gottman, J. M., \& Levenson, R. W. (1992). Marital processes predictive of later dissolution: Behavior, physiology, and health. Journal of Personality and Social Psychology, 63, 221-233.

Greenwald, A. G., Poehlman, T. A., Uhlmann, E., \& Banaji, M. R. (2009). Understanding and using the Implicit Association Test: III. Meta-analysis of predictive validity. Journal of Personality and Social Psychology, 97, 17-41.

Hazan, C., Campa, M., \& Gur-Yaish, N. (2006). What Is Adult Attachment. In M. Mikulincer \& G. S. Goodman (Eds.), Dynamics of romantic love: Attachment, caregiving, and sex (pp. 47-70). New York: Guilford Press. 
Holm, S. (1979). A simple sequentially rejective multiple test procedure. Scandinavian Journal of Statistics, 6, 65-70.

Kenny, D. A., Kashy, D. A., \& Cook, W. L. (2006). Dyadic data analysis. New York: Guilford.

Krämer, N., Bente, G., Eschenburg, F., \& Troitzsch, H. (2009). Embodied conversational agents. Social Psychology, 1, 26-36.

Main, M., \& Goldwyn, R. (1998). Adult Attachment Rating and Classification Systems (Version 6.0). Unpublished manuscript, University of California, Berkeley.

Mallinckrodt, B., \& Chen, E. C. (2004). Attachment and interpersonal impact perceptions of group members: A social relations model analysis of transference. Psychotherapy Research, 14, 210-230.

McCall, C., Blascovich, J., Young, A., \& Persky, S. (2009). Proxemic behaviors as predictors of aggression towards Black (but not White) males in an immersive virtual environment. Social Influence, 4, 138-154.

McClelland, D. C., Koestner, R., \& Weinberger, J. (1989). How do self-attributed and implicit motives differ? Psychological Review, 96, 690-702.

Mikulincer, M. (1998). Adult attachment style and individual differences in functional versus dysfunctional experiences of anger. Journal of Personality and Social Psychology, 74, 513-524.

Mikulincer, M., \& Florian, V. (1998). The relationship between adult attachment styles and emotional and cognitive reactions to stressful events. In J. A. Simpson \& W. S. Rholes (Eds.), Attachment theory and close relationships (pp. 143-165). New York: Guilford Press.

Mikulincer, M., \& Horesh, N. (1999). Adult attachment style and the perception of others: 
The role of projective mechanisms. Journal of Personality and Social Psychology, 76, 1022-1034.

Mikulincer, M., \& Shaver, P. R. (2005). Attachment theory and emotions in close relationships: Exploring the attachment-related dynamics of emotional reactions to relational events. Personal Relationships, 12, 149-168.

Mikulincer, M., Shaver, P. R., \& Pereg, D. (2003). Attachment theory and affect regulation: The dynamics, development, and cognitive consequences of attachment-related strategies. Motivation and Emotion, 27, 77-102.

Rholes, W. S., Simpson, J. A., \& Oriña, M. M. (1999). Attachment and anger in an anxietyprovoking situation. Journal of Personality and Social Psychology, 76, 940-957.

Roisman, G. I., Holland, A., Fortuna, K., Fraley, R. C., Clausell, E., \& Clarke, A. (2007). The Adult Attachment Interview and self-reports of attachment style: An empirical rapprochement. Journal of Personality and Social Psychology, 92, 678-697.

Sanchez-Vives, M. V., \& Slater, M. (2005). From presence to consciousness through virtual reality. Nature Reviews Neuroscience, 6, 332-339.

Saribay, S., \& Andersen, S.M. (2007). Are past relationships at the heart of attachment dynamics? What love has to do with it. Psychological Inquiry, 18, 183-191.

Schallberger, U. (2005). Kurzskala zur Erfassung der Positiven Aktivierung, Negativen Aktivierung und Valenz in Experience Sampling Studien (PANAVA-KS) [Short scales for the assessment of positive affect, negative affect, and valence in experience sampling studies]. Unpublished manuscript, Department of Psychology, University of Zurich, Switzerland.

Schönbrodt, F. D., \& Asendorpf, J. B. (in press a). The challenge of constructing psychologically believable autonomous agents. Journal of Media Psychology.

Schönbrodt, F. D., \& Asendorpf, J. B. (in press b). Virtual social environments as a tool for 
psychological assessment: Dynamics of interaction with a virtual spouse. Psychological Assessment.

Schultheiss, O. C. (2001). An information processing account of implicit motive arousal. In M. L. Maehr \& P. Pintrich (Eds.), Advances in motivation and achievement (Vol. 12: New directions in measures and methods) (pp. 1-41). Greenwich: JAI Press.

Schultheiss, O. C., \& Pang, J. S. (2007). Measuring implicit motives. In R. W. Robins, R. C. Fraley, \& R. F. Krueger (Eds.), Handbook of research methods in personality psychology (pp. 322-344). New York: Guilford Press.

Shaver, P. R., \& Mikulincer, M. (2002). Attachment-related psychodynamics. Attachment \& Human Development, 4, 133-161.

Shaver, P. R., \& Mikulincer, M. (2006). A behavioral system approach to romantic love relationships: Attachment, care-giving, and sex. In R. Sternberg \& K. Weis (Eds.), The new psychology of love (pp. 35-64). New Haven: Yale University Press.

Simpson, J. A., \& Rholes, W. S. (1998). Attachment theory and close relationships. New York: Guilford.

Simpson, J. A., Rholes, W. S., \& Nelligan, J. S. (1992). Support seeking and support giving within couples in an anxiety-provoking situation: The role of attachment styles. Journal of Personality and Social Psychology, 62, 434-446.

Simpson, J. A., Rholes, W. S., Oriña, M. M., \& Grich, J. (2002). Working models of attachment, support giving, and support seeking in a stressful situation. Personality and Social Psychology Bulletin, 28, 598-608.

Simpson, J. A., Rholes, W. S., \& Phillips, D. (1996). Conflict in close relationships: An attachment perspective. Journal of Personality and Social Psychology, 71, 899-914.

Spangler, W. (1992). Validity of questionnaire and TAT measures of need for achievement: Two meta-analyses. Psychological Bulletin, 112, 140-154. 
Vicary, A. M., \& Fraley, R. C. (2007). Choose your own adventure: Attachment dynamics in a simulated relationship. Personality and Social Psychology Bulletin, 33, 1279-1291.

Waters, H. S., \& Waters, E. (2006). The attachment working models concept: Among other things, we build script-like representations of secure base experiences. Attachment and Human Development, 8, 185-197.

Wilcox, R. R. (2005). Introduction to robust estimation and hypothesis testing (2nd ed.). San Diego: Academic Press.

Yee, N., Bailenson, J., \& Rickertsen, K. (2007). A meta-analysis of the impact of the inclusion and realism of human-like faces on user experiences in interfaces. Proceedings of the SIGCHI conference on Human factors in computing systems, 1-10. 
Table 1

Descriptive Statistics of Frequencies of Actions, Physical Distance, Emotional Ascriptions, Attachment Dimensions, and Participants'Emotions

\begin{tabular}{|c|c|c|c|c|c|c|}
\hline \multirow[b]{2}{*}{ Measurement } & \multicolumn{2}{|c|}{ Separation } & \multicolumn{2}{|c|}{ Conflict } & \multicolumn{2}{|c|}{ Illness } \\
\hline & $M$ & $S D$ & $M$ & $S D$ & $M$ & $S D$ \\
\hline \multicolumn{7}{|l|}{ Game index } \\
\hline Interactions overall & $21.30_{\mathrm{a}, \mathrm{b}}$ & 8.37 & $23.05_{\mathrm{a}}$ & 8.84 & $19.48_{\mathrm{b}}$ & 7.15 \\
\hline Interactions with spouse & $15.87_{\mathrm{a}}$ & 5.77 & $18.47_{\mathrm{b}}$ & 7.27 & $15.67_{\mathrm{a}}$ & 5.84 \\
\hline$\%$ Positive actions to spouse & $31.9 \% \mathrm{o}_{\mathrm{a}}$ & 0.11 & $37.3 \% \mathrm{~b}_{\mathrm{b}}$ & 0.13 & $39.5 \%$ & 0.12 \\
\hline$\%$ Negative actions to spouse & $6.7 \%$ & 0.04 & $7.2 \%$ & 0.05 & $6.1 \%$ & 0.03 \\
\hline$\%$ Spouse-directedness & $76.7 \% \%_{a}$ & 0.14 & $81.0 \%$ b & 0.13 & $81.1 \%{ }_{b}$ & 0.12 \\
\hline Support seeking actions & $3.36_{\mathrm{a}}$ & 2.10 & $3.58_{\mathrm{a}}$ & 1.90 & $4.48_{\mathrm{b}}$ & 2.63 \\
\hline Physical distance $^{\mathrm{a}}$ & $1.35_{\mathrm{a}}$ & 0.51 & $1.56_{\mathrm{b}}$ & 0.58 & $1.57_{\mathrm{b}}$ & 0.60 \\
\hline Emotional ascription & $3.95_{\mathrm{a}}$ & 1.39 & $3.62_{\mathrm{b}}$ & 1.55 & $3.59 \mathrm{~b}$ & 1.58 \\
\hline \multicolumn{7}{|l|}{ Participant related measures } \\
\hline Anxiety & 3.05 & 1.23 & 3.06 & 1.24 & 3.07 & 1.32 \\
\hline Avoidance & 2.16 & 0.96 & 2.04 & 1.02 & 1.93 & 0.77 \\
\hline PANAVA: Emotional positivity ${ }^{\mathrm{b}}$ & 0.81 & 1.81 & 0.73 & 1.98 & 0.88 & 1.92 \\
\hline
\end{tabular}

Note. $n=144$ (Separation), 131 (Conflict), 147 (Illness). Different subscripts indicate significant differences $(\mathrm{p}<.05)$.

${ }^{a}$ Distances are $1 / x$ transformed to correct for skewness.

${ }^{\mathrm{b}}$ This difference score is calculated as positive affect - negative affect. Possible range of this difference score is from -6 to +6 . 
Table 2

The Common Part (Dyad and All Together): Multiple Regression of Game Indices onto Attachment Anxiety and Avoidance

\begin{tabular}{|c|c|c|c|c|c|c|}
\hline \multirow[b]{2}{*}{ Index } & \multicolumn{3}{|c|}{ Block 1} & \multicolumn{3}{|c|}{ Block 2} \\
\hline & gender & $\begin{array}{c}\text { relationship } \\
\text { duration }\end{array}$ & $R^{2}$ & Anxiety & Avoidance & $\Delta R^{2}$ \\
\hline \multicolumn{7}{|l|}{ Scene: Dyad } \\
\hline Distance & .04 & -.02 & .00 & -.01 & $.10^{\dagger}$ & .01 \\
\hline Positivity & -.08 & $-.14 * *$ & $.03 * *$ & -.02 & $-.10^{*}$ & $.01 *$ \\
\hline Negativity & .05 & .07 & .01 & .01 & $.29 * * *$ & $.08 * * *$ \\
\hline \multicolumn{7}{|l|}{ Scene: All together } \\
\hline Distance & .07 & -.02 & .01 & .00 & $.09^{\dagger}$ & .00 \\
\hline $\begin{array}{l}\text { Spouse- } \\
\text { directedness }\end{array}$ & -.04 & .06 & .00 & .07 & -.03 & .01 \\
\hline Positivity & -.03 & $-.11 *$ & $.01^{\dagger}$ & .03 & -.04 & .01 \\
\hline Negativity & .00 & $.12 *$ & $.01^{\dagger}$ & .01 & .00 & .00 \\
\hline
\end{tabular}

Note. Each row refers to standardized regression coefficients of the same hierarchical regression $(n=422)$. Relationship duration and physical distance are transformed (log resp. $1 / x)$ to correct for skewness.

$\dagger p<.10 . * p<.05 . * * p<.01 . * * * p<.001$. 
Table 3

Separation Condition: Multiple Regression of Game Indices onto Attachment Anxiety and Avoidance

\begin{tabular}{|c|c|c|c|c|c|c|c|}
\hline \multirow[b]{2}{*}{ Index } & \multicolumn{4}{|c|}{ Block 1} & \multicolumn{3}{|c|}{ Block 2} \\
\hline & $\begin{array}{l}\text { Emotion } \\
\text { base line }\end{array}$ & gender & $\begin{array}{l}\text { relationship } \\
\text { duration }\end{array}$ & $R^{2}$ & Anxiety & Avoidance & $\Delta R^{2}$ \\
\hline \multicolumn{8}{|l|}{ Scene: Separation } \\
\hline Writing a letter & & -.12 & $-.17 *$ & $.06^{*}$ & -.01 & -.07 & .01 \\
\hline $\begin{array}{l}\text { Thinking of the } \\
\text { spouse }\end{array}$ & & .10 & .11 & .02 & $.19^{*}$ & -.13 & $.05^{*}$ \\
\hline $\begin{array}{l}\text { Positive emotion } \\
\text { during separation }\end{array}$ & .11 & .09 & -.06 & .03 & $-.26^{* *}$ & .09 & $.06^{*}$ \\
\hline \multicolumn{8}{|l|}{ Scene: Reunion } \\
\hline Physical distance & & .05 & $-.16^{\dagger}$ & .03 & -.05 & $.18^{*}$ & $.03^{\dagger}$ \\
\hline $\begin{array}{l}\text { Spouse- } \\
\text { directedness }\end{array}$ & & .02 & .11 & .01 & $.15^{\dagger}$ & $-.20 *$ & $.06^{*}$ \\
\hline Positivity & & -.02 & -.07 & .01 & .07 & $-.25 * *$ & $.06^{* *}$ \\
\hline Negativity & & -.02 & $.16^{\dagger}$ & .03 & .10 & .04 & .01 \\
\hline $\begin{array}{l}\text { Positive emotion } \\
\text { after reunion }{ }^{\mathrm{a}}\end{array}$ & -.01 & .00 & .12 & .02 & -.06 & $-.32 * *$ & $.10 * *$ \\
\hline
\end{tabular}

Note. Each row refers to standardized regression coefficients of the same hierarchical regression $(n=144)$. Relationship duration and physical distance are transformed (log resp.

$1 / x)$ to correct for skewness.

a "Positive emotion" refers to emotions participants ascribed to the protagonist.

$\dagger p<.10 .^{*} p<.05 . * * p<.01 . * * * p<.001$. 
Table 4

Conflict Condition: Multiple Regression of Game Indices onto Attachment Anxiety and Avoidance

\begin{tabular}{|c|c|c|c|c|c|c|c|}
\hline \multirow[b]{2}{*}{ Index } & \multicolumn{4}{|c|}{ Block 1} & \multicolumn{3}{|c|}{ Block 2} \\
\hline & $\begin{array}{l}\text { Emotion } \\
\text { base line }\end{array}$ & gender & $\begin{array}{l}\text { relationship } \\
\text { duration }\end{array}$ & $R^{2}$ & Anxiety & Avoidance & $\Delta R^{2}$ \\
\hline \multicolumn{8}{|l|}{ Scene: Conflict } \\
\hline Distance & & .09 & .04 & .01 & .11 & $.23^{*}$ & $.07 *$ \\
\hline $\begin{array}{l}\text { Spouse- } \\
\text { directedness }\end{array}$ & & -.00 & -.14 & .02 & -.01 & $-.26 * *$ & $.06^{*}$ \\
\hline Positivity & & $-.17^{\dagger}$ & -.14 & $.05^{*}$ & -.08 & $-.31 * * *$ & $.10 * * *$ \\
\hline Negativity & & .00 & -.05 & .00 & $.17^{\dagger}$ & -.04 & .03 \\
\hline $\begin{array}{l}\text { Positive emotion } \\
\text { during conflict }^{\mathrm{a}}\end{array}$ & .07 & -.08 & .01 & .01 & $-.25 * *$ & .02 & $.06^{*}$ \\
\hline \multicolumn{8}{|l|}{ Scene: Next day } \\
\hline Distance & & .08 & .04 & .01 & .13 & .02 & .02 \\
\hline $\begin{array}{l}\text { Spouse- } \\
\text { directedness }\end{array}$ & & -.04 & -.01 & .00 & -.05 & -.03 & .01 \\
\hline Positivity & & -.04 & -.13 & .02 & .02 & $-.21 *$ & $.04^{\dagger}$ \\
\hline Negativity & & -.11 & $.21 *$ & $.06^{*}$ & -.06 & $.42 * * *$ & $.16^{* * *}$ \\
\hline $\begin{array}{l}\text { Positive emotion } \\
\text { after conflict }^{\mathrm{a}}\end{array}$ & $.15^{\dagger}$ & .05 & -.07 & .03 & -.11 & $-.23 *$ & $.07^{*}$ \\
\hline
\end{tabular}

Note. Each row refers to standardized regression coefficients of the same hierarchical regression $(n=131)$. Relationship duration and physical distance are transformed (log resp. $1 / x)$ to correct for skewness.

a "Positive emotion" refers to emotions participants ascribed to the protagonist.

$\dagger p<.10 . * p<.05 . * * p<.01 . * * * p<.001$. 
Table 5: Illness Condition: Multiple Regression of Game Indices onto Attachment Anxiety and Avoidance

Block 1

Block 2

\begin{tabular}{|c|c|c|c|c|c|c|c|}
\hline Index & $\begin{array}{l}\text { Emotion } \\
\text { base line }\end{array}$ & gender & $\begin{array}{l}\text { relationship } \\
\text { duration }\end{array}$ & $R^{2}$ & Anxiety & Avoidance & $\Delta R^{2}$ \\
\hline \multicolumn{8}{|l|}{ Scene: Illness } \\
\hline Distance & & .04 & $.15^{\dagger}$ & .02 & $-.22 *$ & .10 & $.05 *$ \\
\hline $\begin{array}{l}\text { Spouse- } \\
\text { directedness }\end{array}$ & & $.16^{\dagger}$ & -.09 & $.04^{\dagger}$ & .03 & $-.15^{\dagger}$ & .02 \\
\hline Positivity & & -.06 & $-.14^{\dagger}$ & .02 & .04 & -.00 & .00 \\
\hline Negativity & & .11 & .14 & .03 & -.08 & .05 & .01 \\
\hline Support seeking & & .08 & -.01 & .01 & -.13 & -.05 & .01 \\
\hline $\begin{array}{l}\text { Positive emotion } \\
\text { during threat }{ }^{\mathrm{a}}\end{array}$ & -.03 & $.39 * * *$ & $.23 * *$ & $.22 * *$ & -.14 & $.13^{\dagger}$ & $.03^{\dagger}$ \\
\hline \multicolumn{8}{|l|}{ Scene: Comfort } \\
\hline Distance & & -.02 & .06 & .00 & -.05 & $.20^{*}$ & $.04^{\dagger}$ \\
\hline $\begin{array}{l}\text { Spouse } \\
\text { directedness }\end{array}$ & & -.07 & -.06 & .01 & .07 & -.04 & .00 \\
\hline Positivity & & $-.20 *$ & $-.16^{*}$ & $.06^{*}$ & .10 & -.10 & .02 \\
\hline Negativity & & .05 & -.12 & .02 & -.07 & -.01 & .00 \\
\hline Support seeking & & -.04 & .04 & .00 & .10 & .02 & .01 \\
\hline $\begin{array}{l}\text { Positive emotion } \\
\text { during comfort }\end{array}$ & $.39 * * *$ & -.05 & .00 & $.18 * * *$ & -.10 & .06 & .01 \\
\hline
\end{tabular}

Note. Each row refers to standardized regression coefficients of the same hierarchical regression $(n=147)$. Relationship duration and physical distance are transformed (log resp. $1 / x)$ to correct for skewness.

a "Positive emotion" refers to emotions participants ascribed to the protagonist.

$\dagger p<.10{ }^{*} p<.05 . * * p<.01 . * * * p<.001$ 


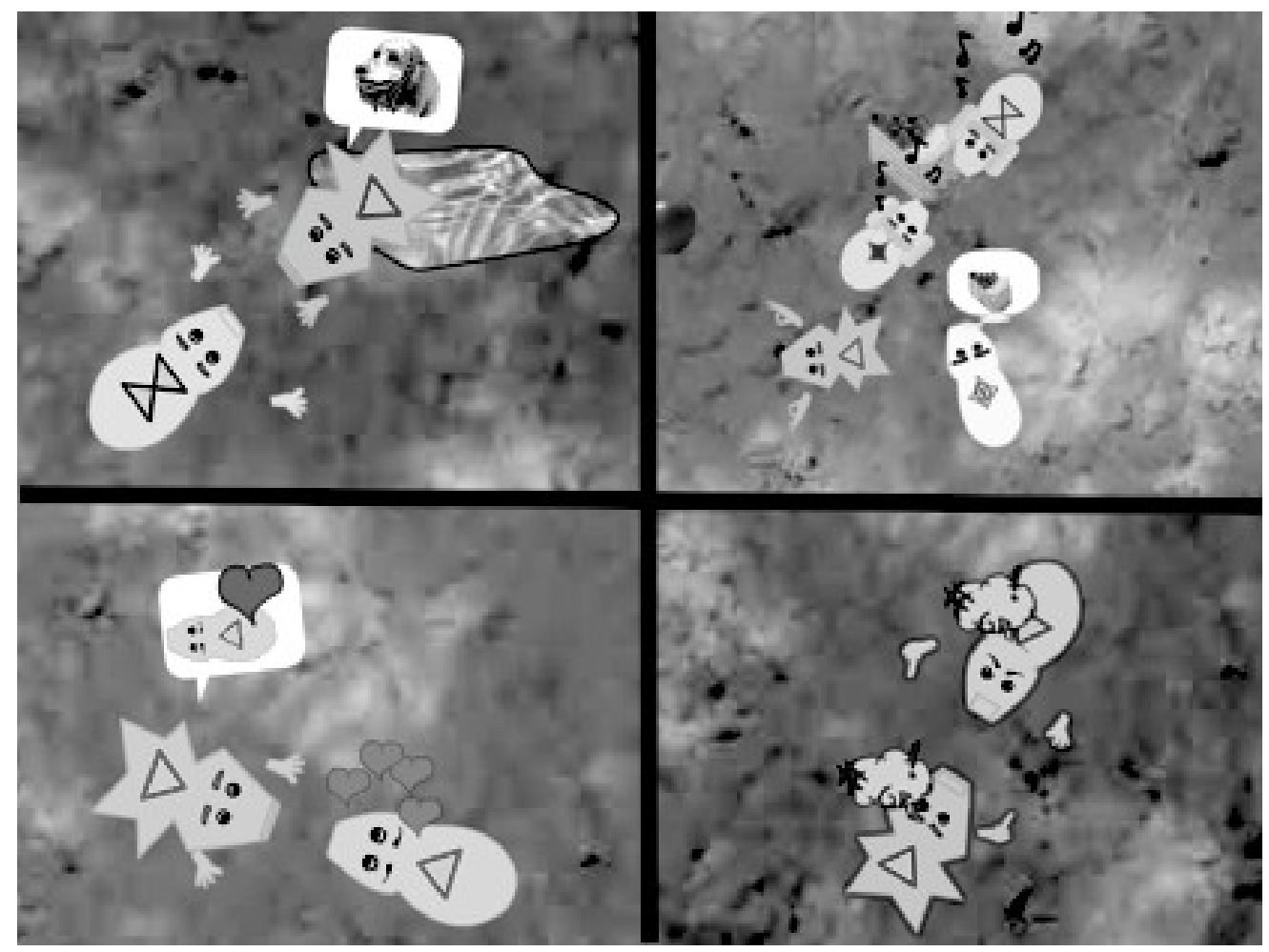

Figure 1: Four exemplary scenes from Simoland. The angular shaped character with the triangle on its back is the agent controlled by the participant. All other characters are autonomous agents. From top left to bottom right: (a) talking about hobbies, (b) a gathering of Simos engaged in different activities, (c) "I love you", (d) a dispute. Adapted from Schönbrodt and Asendorpf (in press, b, Fig. 1). 


$\begin{array}{lll}\text { Separation } & \text { Conflict } & \text { Illness } \\ \text { Condition } & \text { Condition } & \text { Condition }\end{array}$

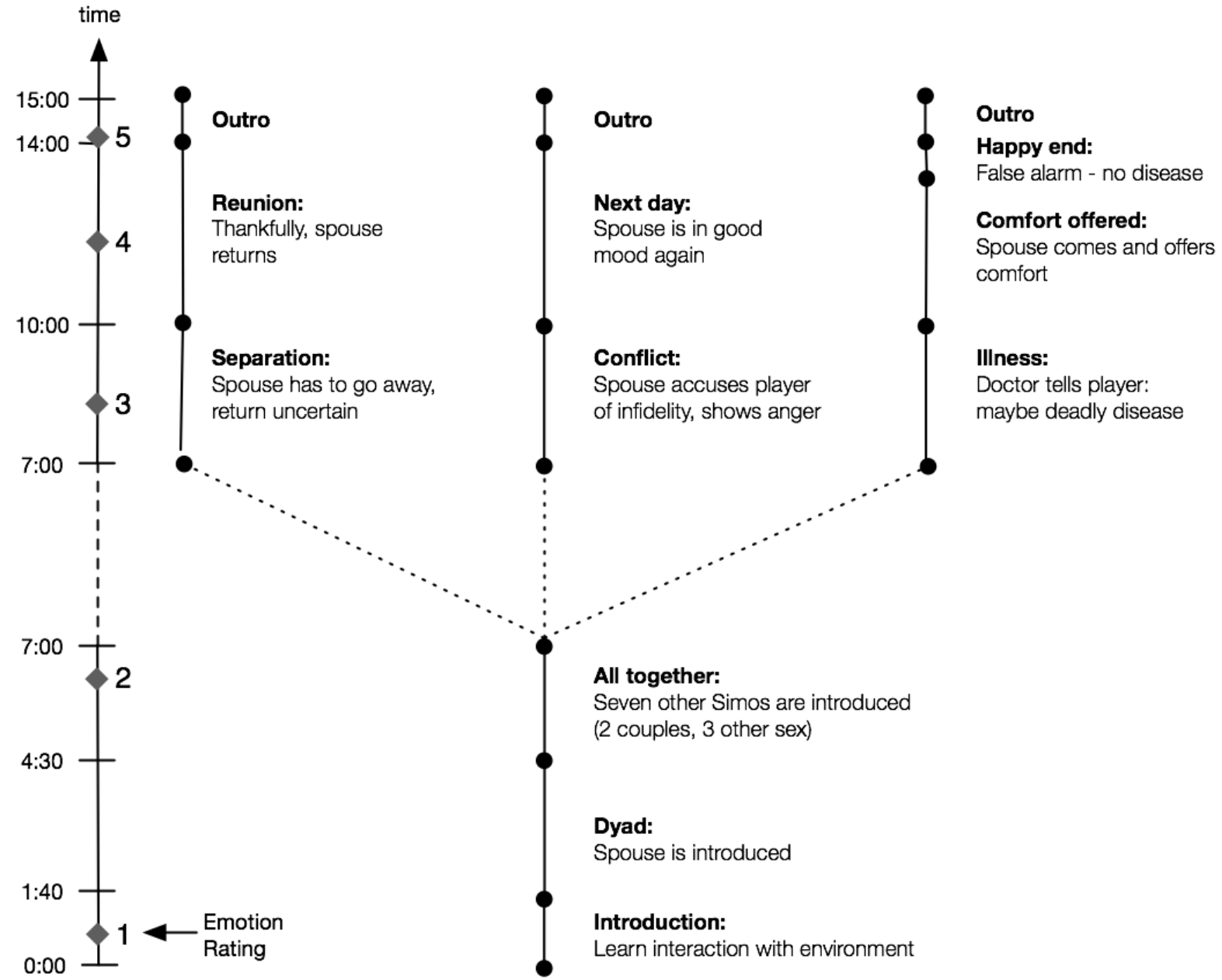

Figure 2: Sequence and timing of the three game scenarios. 


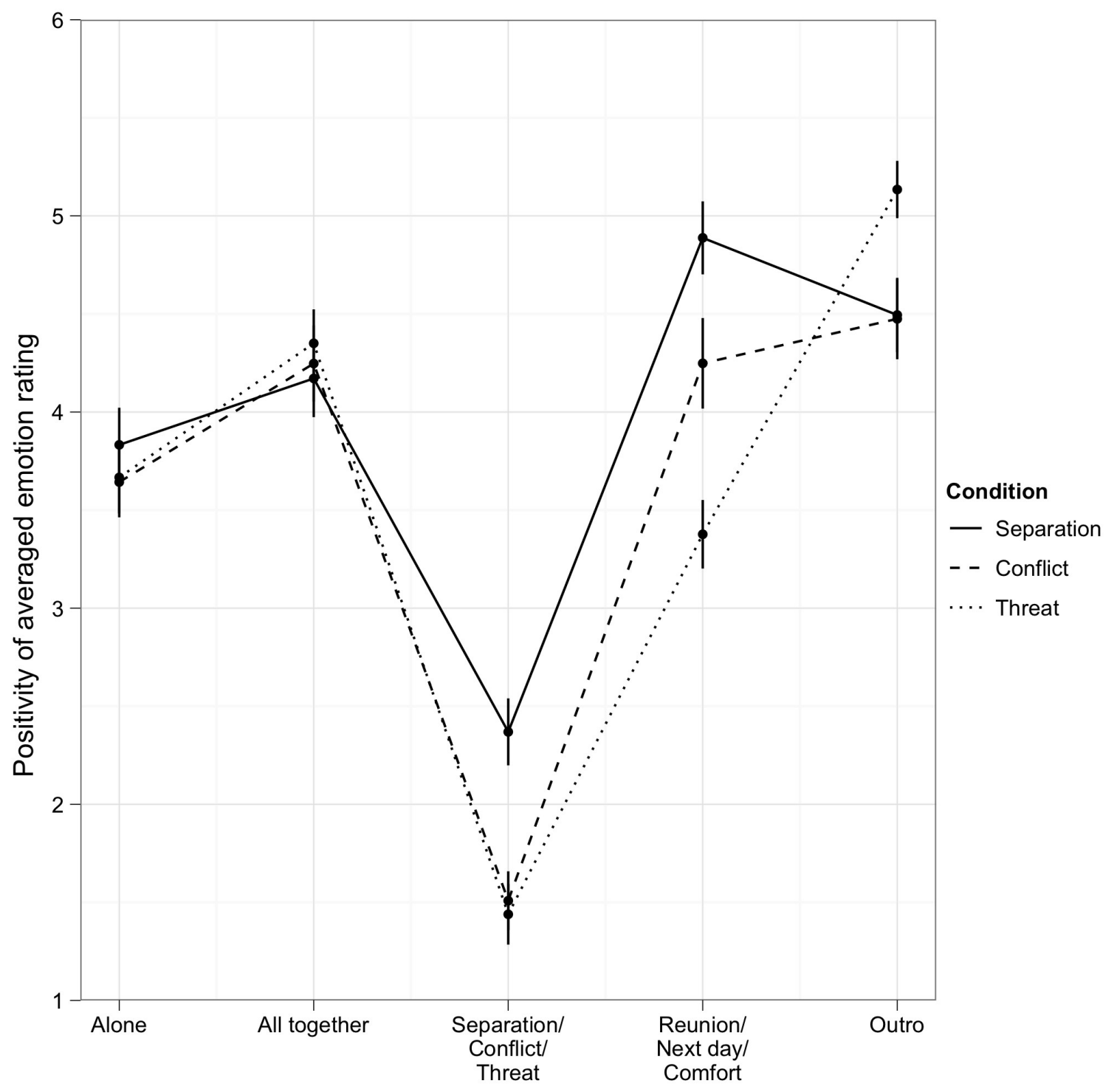


